\title{
Novel MTTP Gene Mutation in a Case of Abetalipoproteinemia with Central Hypothyroidism
}

\author{
(D) Pembe Soylu Ustkoyuncu1, (D) Songul Gokay¹, (D) Esra Eren², (D) Durmus Dogan³, (D) Gokce Yildiz4, (D) Aysegul Yilmaz5, \\ (D) Fatma Turkan Mutlu6 \\ ${ }^{1}$ Kayseri City Hospital, Clinic of Pediatric Nutrition and Metabolism, Kayseri, Turkey \\ ${ }^{2}$ Kayseri City Hospital, Clinic of Pediatric Gastroenterology, Hepatology and Nutrition, Kayseri, Turkey \\ ${ }^{3}$ Kayseri City Hospital, Clinic of Pediatric Endocrinology, Kayseri, Turkey \\ ${ }^{4}$ Kayseri City Hospital, Clinic of Pediatrics, Kayseri, Turkey \\ ${ }^{5}$ Kayseri City Hospital, Clinic of Pediatric Genetic, Kayseri, Turkey \\ ${ }^{6}$ Kayseri City Hospital, Clinic of Pediatric Hematology and Oncology, Kayseri, Turkey
}

\section{What is already known on this topic?}

The coexistence of abetalipoproteinaemia (ABL) and peripheral hypothyroidism has been previously reported.

\section{What this study adds?}

The coexistence of ABL and central hypothyroidism has not been reported previously. A homozygous novel mutation [C.506A > T (p.D169V)] was detected in the MTTP gene. Our patient had dysmorphic features which is very rare in cases of ABL.

\begin{abstract}
Abetalipoproteinaemia (ABL) is an autosomal recessive disorder characterized by very low plasma concentrations of total cholesterol and triglyceride (TG). It results from mutations in the gene encoding microsomal TG transfer protein (MTTP). A nine-month-old girl was admitted to hospital because of fever, cough, diarrhea and failure to thrive. She had low cholesterol and TG levels according to her age. The peripheral blood smear revealed acanthocytosis. Thyroid function test showed central hypothyroidism. Cranial magnetic resonance imaging revealed the retardation of myelination and pituitary gland height was $1.7 \mathrm{~mm}$. A homozygous novel mutation [C.506A $>\mathrm{T}$ (p.D169V)] was detected in the MTTP gene. Vitamins A, D, E, and K and levothyroxine were started. The coexistence of ABL and central hypothyroidism has not previously been reported. A homozygous novel mutation [c.506A > T (p.D169V)] was detected in the MTTP gene. Keywords: Abetalipoproteinaemia, central hypothyroidism, MTTP gene, novel mutation
\end{abstract}

\section{Introduction}

Abetalipoproteinaemia (ABL) (ABL; OMIM 200100) is an autosomal recessive disorder characterized by very low plasma concentrations of total cholesterol (TC) and triglyceride (TG). The disorder was first described in 1950 by Bassen and Kornzweig (1) in a patient with atypical retinitis pigmentosa. ABL results from mutations in the gene encoding microsomal TG transfer protein (MTTP). Patients with $A B L$ often present with a range of symptoms such as failure to thrive, steatorrhea, hepatomegaly, loss of night and/or color vision, acquired atypical pigmentation of the retina, spinocerebellar ataxia, coagulopathy and myopathy, including fat malabsorption and manifestations of fat soluble vitamin deficiencies $(2,3)$. Early detection and a low fat diet with fat soluble vitamin supplementation can prevent the neurological and ophthalmological complications (4).

Here, we report the coexistence of $\mathrm{ABL}$ and central hypothyroidism. This has not been previously reported. In addition, this patient had dysmorphic features. Coexistence of ABL and dysmorphic features is very rare. We detected a novel homozygous mutation in the MTTP gene. 


\section{Case Report}

A nine-month old girl was admitted to our hospital because of fever, cough, diarrhea (11 or 12 episodes a day), and failure to thrive. She was born by normal delivery at term with a birth weight of 3200 grams after an uneventful pregnancy. The patient was the second child of a non-consanguineous Turkish couple, who also had a 5-year-old healthy daughter.

At presentation her body weight was $4.7 \mathrm{~kg}$ [standard deviation (SD): -3.5], height was $62.5 \mathrm{~cm}$ (SD: -1.7), head circumference was $39 \mathrm{~cm}$ (3\% percentile). Relative index was 71.2 .

She was pale, her hair was thin and weak, her subcutaneous adipose tissue was decreased. She had rales in the middle zone of her left lung. Her abdomen was distended and bowel loops were prominent. She also had umbilical and bilateral inguinal hernia. She had dysmorphic features including hypertelorism, frontal bossing, triangular face and retromicrognathia (Figure 1).

Her head control was complete but she could not sit without support. Deep tendon reflexes were normoactive.

Laboratory investigations revealed: hemoglobin level was $9.8 \mathrm{~g} / \mathrm{dL}$; leukocyte count was $14820 / \mathrm{mm}^{3}$; and platelet count was $363000 / \mathrm{mm}^{3}$. Serum transaminases were mildly elevated with aspartate aminotransferase of $105 \mathrm{U} / \mathrm{L}$,

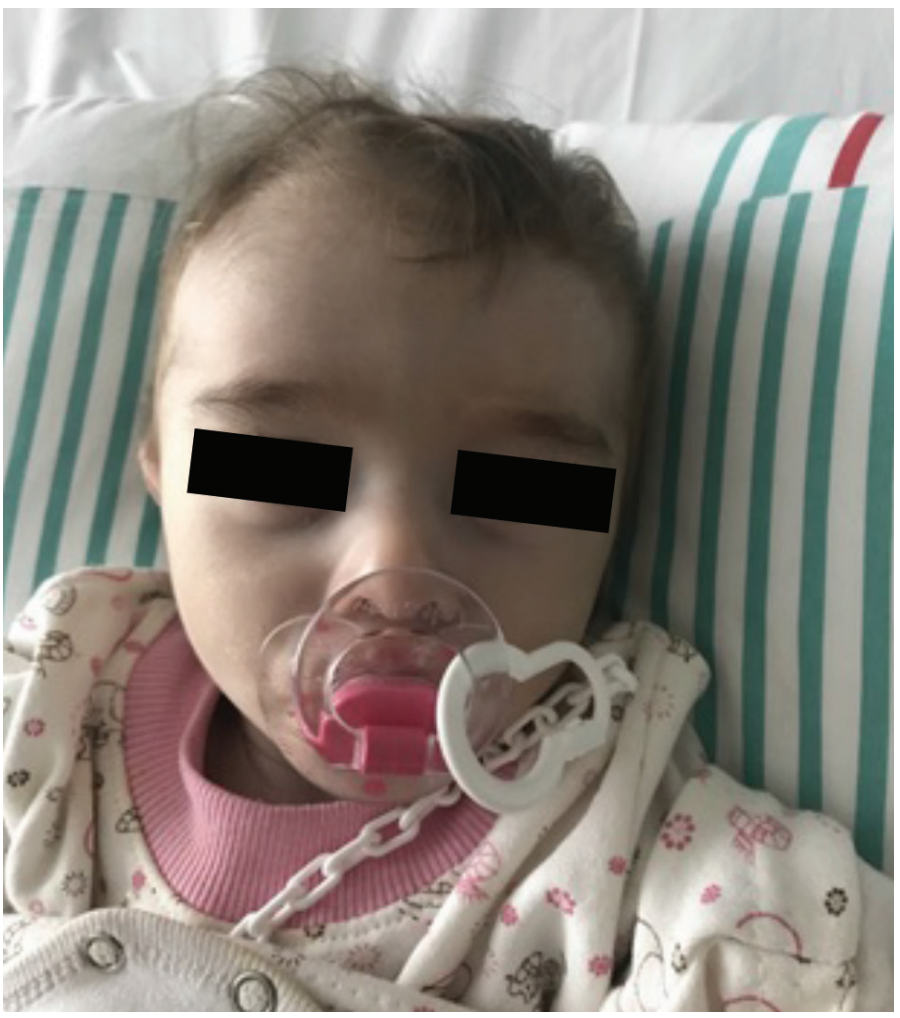

Figure 1. Dysmorphic features including hypertelorism, frontal bossing, triangular face and retromicrognaty (normal range: 0-33) and alanine aminotransferase of 112 U/L (normal range: 0-32).

Vitamin D concentration was $11.6 \mu \mathrm{g} / \mathrm{L}$ (normal >30), alkaline phosphatase concentration was $99 \mathrm{u} / \mathrm{L}$ (normal range: 142-335), calcium concentration was $9.03 \mathrm{mg} /$ dL (normal range: 8.6-10.2), phosphorus concentration was $3.15 \mathrm{mg} / \mathrm{dL}$ (normal range: 2.45-4.5) and parathyroid hormone concentration was $60 \mathrm{mg} / \mathrm{L}$ (normal range: 15-65).

TORCH screen was negative and other infections due to hepatotropic viruses or human immunodeficiency virus were ruled out. The results of coagulation tests, renal functions and electrolytes were also normal. She was hospitalized three times for bronchiolitis. Cystic fibrosis was considered in this patient due to malnutrition, recurrent bronchiolitis and elevation of liver function tests. Molecular genetic analysis of the CFTR gene was normal. Stool examination revealed no reducing substances and showed fat droplets. The search for pathogenic bacteria or parasites was negative. Normal levels of anti-endomysial antibodies ruled out celiac disease and basic metabolic tests including ammonia, lactate, pyruvate, blood acyl carnitine profile and amino acid analysis, urinary organic acid analysis, homocysteine and biotinidase activity were all normal. Congenital immune deficiency was ruled out. Immunoglobulin (Ig) profile (quantitative measurement of IgA, IgM, IgG and IgE), CD markers (CD3, CD19, CD56) and fagotest were normal. She had low cholesterol and TG concentrations with TC of $26 \mathrm{mg} / \mathrm{dL}$ (normal range: 3-200) and TG of $9 \mathrm{mg} / \mathrm{dL}$ (normal range: 0-200) according to her age. The peripheral blood smear revealed acanthocytosis (Figure 2).

The concentrations of vitamin $\mathrm{E}$ at $0.87 \mathrm{mg} / \mathrm{L}$ (normal range: 6.6-14.3), vitamin A at $71 \mathrm{ug} / \mathrm{L}$ (normal range: 316820 ) and vitamin D at $11.6 \mathrm{ug} / \mathrm{L}$ (normal values $>30$ ) were

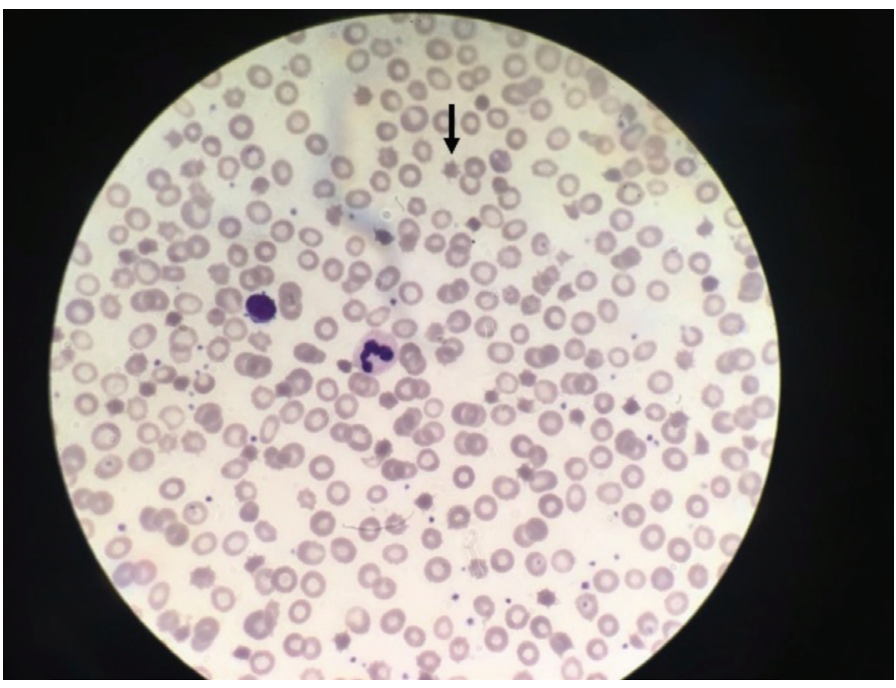

Figure 2. Acanthocytosis in the peripheral blood smear 
very low. ABL was considered in this patient with these clinical and laboratory findings. Abdominal ultrasonography revealed multiple small stones $(<3 \mathrm{~mm})$ in both kidneys and ophthalmologic examination was normal.

Vitamin A (200 IU/kg/day), D (1200 IU/day), E (100 IU/kg/ day), and $\mathrm{K}$ (5 mg/week) were started. High caloric (150 $\mathrm{kcal} / \mathrm{kg} /$ day), low fat diet (15 \%) with medium chain TG and Basic $\mathrm{F}^{\circledR}$ formula were also started.

Thyroid stimulating hormone (TSH) was $1.4 \mathrm{mU} / \mathrm{L}$ (normal range: 0.73-8.35) and thyroxine (T4) level was $8.7 \mathrm{ng} / \mathrm{L}$ (normal range: 9.2-19.9). Control TSH level was $3 \mathrm{mU} / \mathrm{L}$, and T4 level was $7.4 \mathrm{ng} / \mathrm{L}$. Therefore, levothyroxine $(12.5 \mathrm{mcg} /$ day) was started. After the treatment, thyroid function tests were studied intermittently and levothyroxine dose was increased to $37.5 \mathrm{mcg} /$ day. Free triiodothyronine (fT3) level was $3.55 \mathrm{ng} / \mathrm{L}$ (normal range: $2.15-5.83$ ).

Follicle-stimulating hormone, luteinizing hormone, adrenocorticotropic hormone (ACTH), cortisol and prolactin levels were evaluated for multiple pituitary insufficiency in addition to central hypothyroidism. Low dose ACTH stimulation test was performed due to a basal cortisol concentration of $10.1 \mu \mathrm{g} / \mathrm{dL}$ (normal > 15). The peak cortisol values on low dose ACTH stimulation test were $35.8 \mu \mathrm{g} / \mathrm{dL}$ and evaluated as an adequate cortisol response. Prolactin concentration was $15.12 \mu \mathrm{g} / \mathrm{L}$ and accepted as normal. Insulin-like growth factor-1 (IGF-1) concentration was 8.53 $n g / m L$ (SD -4.28). This low IGF-1 level was attributed to malnutrition. IGF-1 evaluation was planned according to anthropometric follow-up. Cranial magnetic resonance imaging (MRI) revealed the retardation of myelination and pituitary gland height was $1.7 \mathrm{~mm}$ (Figure 3). A further sagittal MRI view of the pituitary gland is shown in Figure 4.

Endoscopy was performed to support the diagnosis due to delay in obtaining the molecular genetic analysis. Macroscopic findings of endoscopy included normal mucosa of esophagus and stomach but "snow-like" appearance and pathologic findings were found in duodenum. Microscopic study showed widespread intracytoplasmic vacuolized degeneration of the villi.

MTTP gene analysis revealed a novel homozygous pathogenic variant [c.506A > T (p. D169V)]. In silico analysis indicated that the $\mathrm{D} 169 \mathrm{~V}$ substitution in MTTP was probably damaging. She is now 15 months old, her body weight was 8.9 kilograms (10-25\% percentile) and height was 72.5 $\mathrm{cm}$ (3\% percentile). She is receiving vitamin A (250 IU/kg/ day), vitamin D (1200 IU/day), vitamin E (150 IU/kg/day), vitamin $\mathrm{K}$ (5 mg/week) and levothyroxine ( $37.5 \mathrm{mcg} /$ day). She continues with a low-fat $(15 \%)$ and high-calorie diet. Vitamin $\mathrm{A}$ and $\mathrm{E}$ concentrations, together with thyroid function $(\mathrm{TSH}=3.9 \mathrm{mU} / \mathrm{L}, \mathrm{T} 4=14 \mathrm{ng} / \mathrm{L}$ ) and coagulation tests, were normal. Stool number decreased significantly (2 or 3 episodes a day). Neurological examination is improved and she is standing and walking with support. This case report was written after receiving informed consent from the family.

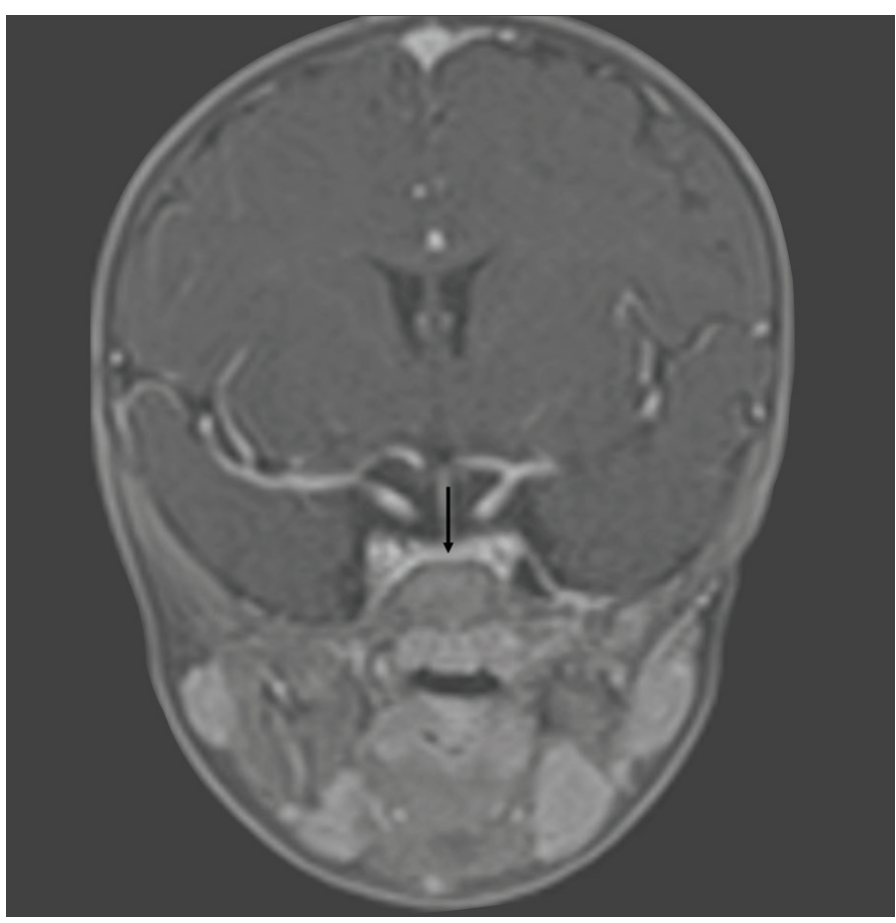

Figure 3. The appearance of pituitary gland

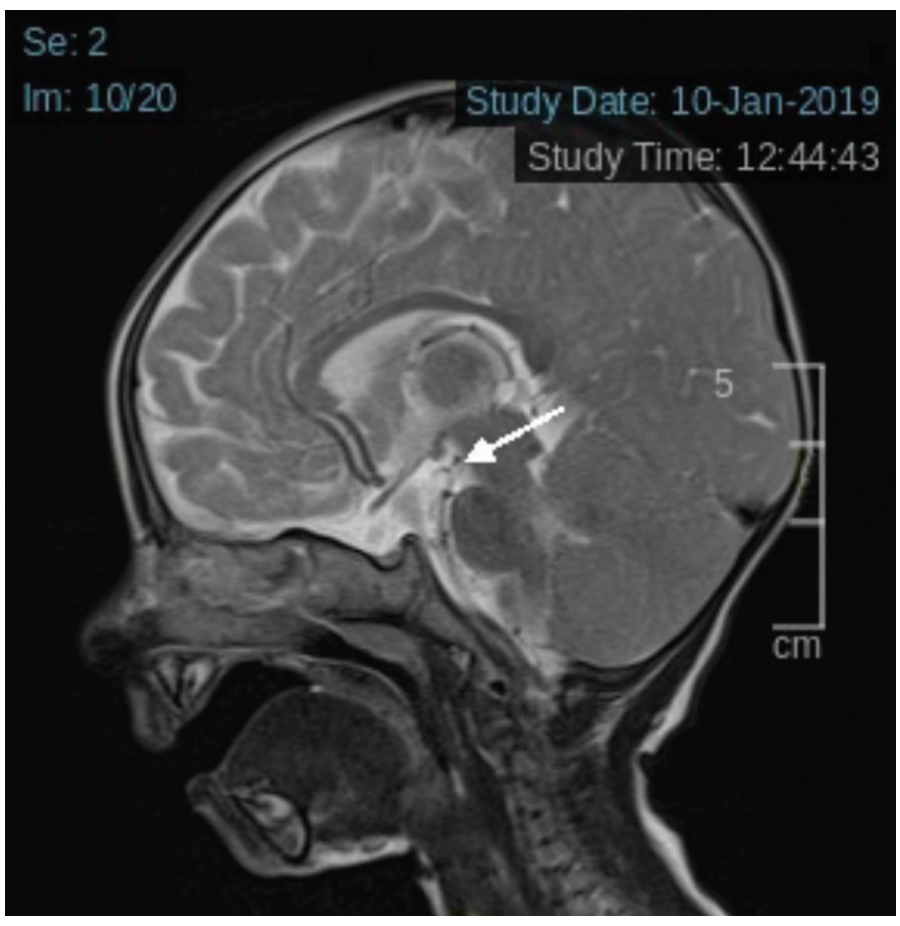

Figure 4. Sagittal magnetic resonance imaging image of the pituitary gland 


\section{Discussion}

Homozygous hypolipoproteinemia, and chylomicron retention disease have similar clinical findings with ABL. The diagnosis of ABL appeared to be the most likely in view of the normal plasma levels of TC and TG levels found in the parents, which suggested an autosomal recessive transmission. Our patient had also low levels of TG. For this reason, we sequenced the MTTP gene. MTTP gene analysis revealed a homozygous novel mutation $[\mathrm{c} .506 \mathrm{~A}>\mathrm{T}$ ( $\mathrm{p}$. D169V)].

More than 30 mutations in MTTP have been identified. The majority are point mutations resulting in either splicing errors or premature truncations (5). Our case had a point mutation in MTTP.

There were some clinical features rarely associated with ABL in the present case. Facial dimorphism and psychomotor retardation have not often been described. It has been suggested that psychomotor retardation occurs due to hypothyroidism. Hasosah et al (6) reported dysmorphic features including hypertelorism, short nose, long philtrum, and thin upper lip in an 18-month-old male ABL patient.

Fat malabsorption causes a combination of unabsorbed fatty acids with calcium ions in the intestinal lumen leading to excessive absorption of oxalate. Rashtian et al (2) reported nephrolithiasis in a 12-months-old male infant, similar to the findings in our patient.

Hypothyroidism can be associated with ABL. Al-Mahdili et al (7) reported a mild case of ABL in association with subclinical hypothyroidism in a 32-year-old female. However, coexistence of ABL and central hypothyroidism has not been previously reported.

Euthyroid sick syndrome (ESS) is characterized by modification of thyroid hormone homeostasis due to nonthyroidal diseases. ESS has been described in liver disease, renal failure, after stress or surgery, in malnutrition or in malignancies. ESS is present if free fT3 was below the lower limit and free T4 was within the normal or low limits, while TSH was in the normal range (8). fT3 level of our patient was $3.55 \mathrm{ng} / \mathrm{L}$ (normal range: 2.15-5.83). Therefore, ESS was ruled out.

Krysiak and Okopie (9) reported that untreated or poorly managed ABL can impair the production of steroid hormones and cause some endocrine disorders such as chronic adrenal failure and hypergonadotropic hypogonadism.

Illingworth and Orwoll (10) reported that suboptimal response to corticotrophin stimulation maintained stable levels of plasma cortisol and showed no evidence of adrenal insufficiency with prolonged corticotrophin stimulation in ABL and hypobetalipoproteinaemia. The same group also showed that (11) a total absence of low density lipoprotein (LDL) does not impair adrenal steroidogenesis in the basal state and highlighted that plasma LDL serves as an important source of cholesterol for adrenal corticosteroid synthesis under conditions of sustained stimulation with ACTH (12).

Triantafillidis et al (13) and Illingworth et al (14) reported that patients with ABL have reduced levels of progesterone. This was attributed to low levels of serum LDL cholesterol. Reduced levels of leptin and IGF-1 are probably attributed to the impairment of nutritional status. Arem et al (15) reported that severe LDL cholesterol insufficiency impairs the initial glucocorticoid response to ACTH stimulation, but not overall cortisol production during sustained $\mathrm{ACTH}$ stimulation. Severe LDL cholesterol insufficiency may also contribute to the reduction of testosterone in chronically ill patients.

Ocular manifestations are variable, retinitis pigmentosa, ophthalmoplegia, ptosis, nystagmus, peripapillary chorioretinal degeneration, macular atrophy have been reported $(16,17)$. The absence of ocular manifestations in our patient was attributed to the fact that they may appear at any time during the first two decades of life.

Hepatic involvement may include steatosis and elevated serum transaminase levels. In a few cases of $A B L$, hepatic injury progressed to fibrosis and cirrhosis, requiring transplantation $(4,18)$. The hepatic manifestation in our patient was limited to elevated levels of serum transaminases.

\section{Conclusion}

ABL is a rare disease of lipoprotein metabolism. Symptoms can be debilitating in most patients. Life expectancy is reduced without treatment. The coexistence of the disorder and central hypothyroidism has not been previously reported. ABL in this case was due to a novel homozygous mutation in the MTTP gene.

\section{Ethics}

Informed Consent: Written consent form was obtained from the parents.

Peer-review: Externally and internally peer-reviewed.

\section{Authorship Contributions}

Surgical and Medical Practices: Pembe Soylu Ustkoyuncu, Esra Eren, Durmus Dogan, Concept: Pembe Soylu Ustkoyuncu, Aysegul Yilmaz, Esra Eren, Design: Pembe Soylu Ustkoyuncu, Durmus Dogan, Data Collection or 
Processing: Songul Gokay, Fatma Turkan Mutlu, Gokce Yildiz, Analysis or Interpretation: Aysegul Yilmaz, Durmus Dogan, Literature Search: Aysegul Yilmaz, Songul Gokay, Fatma Turkan Mutlu, Writing: Pembe Soylu Ustkoyuncu, Gokce Yildiz.

Financial Disclosure: The authors declared that this study received no financial support.

\section{References}

1. Bassen FA, Kornzweig AL. Malformation of the erythrocytes in a case of atypical retinitis pigmentosa. Blood 1950;5:381-387.

2. Rashtian P, Najafi Sani M, Jalilian R. A Male Infant with Abetalipoproteinemia: A Case Report from Iran. Middle East J Dig Dis 2015;7:181-184.

3. Zamel R, Khan R, Pollex RL, Hegele RA. Abetalipoproteinemia: two case reports and literature review. Orphanet J Rare Dis 2008;8;3:19.

4. Lee J, Hegele RA. Abetalipoproteinemia and homozygous hypobetalipoproteinemia: a framework for diagnosis and management. J Inherit Metab Dis 2014;37:333-339. Epub 2013 Nov 28

5. Miller SA, Burnett JR, Leonis MA, McKnight CJ, van Bockxmeer FM, Hooper AJ. Novel missense MTTP gene mutations causing abetalipoproteinemia. Biochim Biophys Acta 2014;1842:1548-1554.

6. Hasosah MY, Shesha SJ, Sukkar GA, Bassuni WY. Rickets and dysmorphic findings in a child with abetalipoproteinemia. Saudi Med J 2010;31:1169-1171.

7. Al-Mahdili HA, Hooper AJ, Sullivan DR, Stewart PM, Burnett JR. A mild case of abetalipoproteinaemia in association with subclinical hypothyroidism. Ann Clin Biochem 2006;43:516-519.

8. Duyu A, Çıtak EC, Ak E, Küpeli S, Yağcı Küpeli B, Bayram İ, Sezgin G, Eskendari G, Sezer K. Prevalence and Related Factors of Euthyroid Sick Syndrome in Children with Untreated Cancer According to Two Different Criteria. J Clin Res Pediatr Endocrinol 2018;31;10:198-205.
9. Krysiak R, Okopie B. Chronic adrenal failure and hypergonadotropic hypogonadism in a patient with abetalipoproteinemia. Eur Rev Med Pharmacol Sci 2012;16:95-97.

10. Illingworth DR, Orwoll ES. Low-density lipoproteins and adrenal cortisol production: studies in abetalipoproteinaemia and hypobetalipoproteinaemia. Biochem Soc Trans 1981;9:50.

11. Illingworth DR, Kenny TA, Connor WE, Orwoll ES. Corticosteroid production in abetalipoproteinemia: evidence for an impaired response ACTH. J Lab Clin Med 1982;100:115-126.

12. Illingworth DR, Kenny TA, Orwoll ES. Adrenal function in heterozygous and homozygous hypobetalipoproteinemia. J Clin Endocrinol Metab 1982;54:27-33.

13. Triantafillidis JK, Kottaras G, Peros G, Merikas E, Gikas A, Condilis N, Konstantellou E. Endocrine function in abetalipoproteinemia: a study of a female patient of Greek origin. Ann Ital Chir 2004;75:683-690.

14. Illingworth DR, Corbin DK, Kemp ED, Keenan EJ. Hormone changes during the menstrual cycle in abetalipoproteinemia: reduced luteal phase progesterone in a patient with homozygous hypobetalipoproteinemia. Proc Natl Acad Sci USA 1982;79:6685-6689.

15. Arem R, Ghusn H, Ellerhorst J, Comstock JP. Effect of decreased plasma low-density lipoprotein levels on adrenal and testicular function in man. Clin Biochem 1997;30:419-424.

16. Alshareef RA, Bansal AS, Chiang A, Kaiser RS. Macular atrophy in a case of abetalipoproteinemia as only ocular clinical feature. Can J Ophthalmol 2015;50:43-46.

17. Yee RD, Cogan DG, Zee DS. Ophthalmoplegia and dissociated nystagmus in abetalipoproteinemia. Arch Ophthalmol 1976;94:571575 .

18. Di Filippo M, Moulin P, Roy P, Samson-Bouma ME, Collardeau-Frachon S, Chebel Dumont S, Peretti N, Dumortier J, Zoulim F, Fontanges T, Parini R, Rigoldi M, Furlan M, Mancini G, Bonnefont-Rousselot D, Bruckert E, Schmitz J, Scoazec JY, Charrière S, Villar-Fimbel S, Gottrand F, Dubern B, Doummar D, Joly F, Liard-Meillon ME, Lachaux A, Sassolas A. Homozygous MTTP and APOB mutations may lead to hepatic steatosis and fibrosis despitemetabolic differences in congenital hypocholesterolemia. J Hepatol 2014;61:891-902. Epub 2014 May 16 